\title{
Editor Comment from the Video Section Editor
}

Dear readers,

I want to take this opportunity to wish all of you and your families very happy holidays and best wishes for the upcoming year. This year has been another very successful year for the International Brazilian Journal of Urology and the video section of our journal specifically. I would like to congratulate Dr. Sidney Glina editor-in-chief and his entire editorial team for the continued success of our journal as a highly regarded international peer reviewed journal in the scientific literature. This year we have selected again what are considered the top 3 videos published in the International Brazilian Journal of Urology. Nominations for best videos of the year have been made by editorial consultants of the video section in a completely blinded manner selecting what are considered the most original and best depicted surgical technique or approach. These selections were then tabulated and thereafter we attributed a 1st, 2nd, and 3rd prize for best videos of the year and here they are.

First prize: The group of Dr. Cesar Britto from Brazil are awarded the first prize "Retrocaval ureter repair" (http://www.brazjurol.com.br/vis.asp?code=2896) for their truly novel laparoendoscopic single site surgery to repairing a retrocaval ureter. This video very accurately depicts how single site minimally invasive surgery can be used to do such refined surgical procedures. The applications of single surgery are clearly evolving and as demonstrated in the present case, advanced laparoscopic skills can allow such cases to be undertaken with excellent functional and cosmetic results.

Second prize: The group of Cesar Britto is awarded as well the second prize "Hemi NX for horseshoe kidney" (http://www.brazjurol.com.br/vis.asp?code=2964) as a result of their excellent depiction of a pure laparoscopic technique in the management of large renal tumor in a horseshoe kidney. As most authors will realize, the surgical approach to a horseshoe kidney can be quite challenging in consequence to the aberrant anatomic location and vascular anatomy. The authors of this video have demonstrated how such challenging cases can be done using a pure laparoscopic approach with excellent treatment outcomes.

Third prize: The pediatric urology group from Dr Hubert Swana and colleagues from the University of South Florida have depicted a truly original transurethral neo-orifice (TUNO) approach to managing upper pole renal obstruction "TUNO abstract" (http:// www.brazjurol.com.br/vis.asp?code=2897). The authors have delineated a very original technique to managing such issues in children using a "scalpless" technique i.e. natural orifice surgery is essentially what is being employed. As urologists, we often endoscopically manage bladder tumors, benign prostatic hyperplasia, and nephrolithiasis but in this case the indication of such endoscopic surgery is broadened while maintaining great results. 


\section{EDITOR'S

I would like to conclude this newletter by once again thanking all of our submitters and readers of the International Brazilian Journal of Urology for their continued support and dedication to the video section. I believe the upcoming year will be a truly defining year for our section as we are working on developing an electronic platform for video submissions and likely will be launching other resources to promote accepted videos across several international media resources which would allow urologists across the world to comment on the novelty and benefits/drawbacks of specific surgical approaches depicted in these videos.

Very best wishes,

\section{Philippe E. Spiess, MD}

Video Section Editor,

International Brazilian Journal of Urology

Associate Professor, Department of Genitourinary

Oncology

Moffitt Cancer Center 